\title{
Bootstrap innovational outlier unit root tests in dependent panels
}

\author{
Mauro Costantini ${ }^{\mathrm{a}}$, Luciano Gutierrez ${ }^{\mathrm{b}, *}$

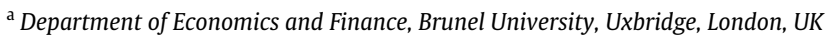 \\ ${ }^{\mathrm{b}}$ Department of Economics and Woody Plant Ecosystems, University of Sassari, Via E. De Nicola 1, 07100 Sassari, Italy
}

\section{A R T I C LE I N F O}

\section{Article history:}

Received 12 November 2010

Received in revised form

1 November 2011

Accepted 30 November 2011

Available online 13 December 2011

\section{JEL classification:}

$\mathrm{C} 22$

$\mathrm{C} 23$

\section{Keywords:}

Nonstationary panel data

Structural break

Innovational outlier model

Bootstrap

\begin{abstract}
A B S T R A C T
In this paper, we propose new simple innovational outlier (IO) panel unit root tests with a break. A bootstrap method for dealing with cross-sectional dependence is provided and small sample properties of the bootstrap tests are investigated by Monte Carlo experiments. The panel innovational outlier unit tests are then applied to a panel of 22 OECD inflation rates.
\end{abstract}

(C) 2011 Elsevier B.V. All rights reserved.

\section{Introduction}

Perron (1989) develops unit root tests that are designed to have power against the trend-break stationary alternative. However the intrinsic problem of the Perron's (1998) approach is that the parameters of the test regression have different interpretations under the null and alternative hypotheses. To deal with this problem, Popp (2008) formulates the data generating process as an unobserved component model and develops a new Perrontype innovational outlier test for several model specifications. In this paper, we extend to panel data the new Perron-type test for the case of a shift in the intercept and not-trending data using a combination-based approach proposed by Choi (2001). Three new panel innovational outlier unit root tests are proposed. They are easy to implement and offers some advantages: (i) there is no need for a balanced panel, so that individual time series may come in different lengths and span different sample periods; (ii) the tests allow for heterogeneous panels since the stochastic as well as the non stochastic components can be different across individual time series; (iii) more powerful panel unit root tests can be obtained with respect to the univariate counterpart by exploiting the crosssection variation, see Baltagi and Kao (2000).

\footnotetext{
* Corresponding author. Tel.: +39 079229256; fax: +39 079229356.

E-mail address: lgutierr@uniss.it (L. Gutierrez).
}

Since a serious drawback of the methodology advocated in Choi (2001) is that it is based on the hypothesis of crosssectional independence, we use a sieve bootstrap procedure to deal with cross-sectional dependence. Small sample properties of the bootstrap panel innovational outlier unit root tests are investigated by Monte Carlo experiments. The new panel tests are applied to 22 OECD quarterly inflation rates. Evidence of stationarity is found.

The paper is organized as follows. Section 2 presents the model and the three panel combination tests. Section 3 describes the bootstrap procedure. Section 4 presents a Monte Carlo analysis. Section 5 contains the empirical application.

\section{The Perron-type IO panel unit root tests}

\subsection{The model}

Consider the following unobserved component model:

$y_{i t}=d_{i t}+u_{i t}$,

$u_{i t}=\rho_{i} u_{i t-1}+\varepsilon_{i t}$,

$\varepsilon_{i t}=\Psi_{i}^{*}(L) e_{i t}=A_{i}^{*}(L)^{-1} B_{i}(L) e_{i t}$,

with $e_{i t} \sim$ i.i.d. $\left(0, \sigma_{i}^{2}\right)$ and $i=1, \ldots, N$ and $t=1, \ldots, T$. The lag polynomial $\Psi_{i}^{*}(L)$ can be factored as $\Psi_{i}^{*}(L)=A_{i}^{*}(L)^{-1} B_{i}(L) . A_{i}^{*}(L)$ and $B_{i}(L)$ are lag polynomials of order $p$ and $q$, respectively. It is 
assumed that $A_{i}^{*}(L)$ and $B_{i}(L)$ have all roots outside the unit circle. The deterministic component is specified as:

$d_{i t}=\alpha_{i}+\Psi_{i}^{*}(L) \theta_{i} D U_{i t}$,

where $D U_{i t}=1$ if $\left(t>T B_{i}\right)$ and 0 otherwise, with $T B_{i}=\lambda_{i} T$ and $\lambda_{i}\left(0<\lambda_{i}<1\right)$ being the break date and the break fraction respectively. The reduced form of the structural model (1) can be obtained by nesting the null and alternative hypotheses as follows:

$$
\begin{aligned}
y_{i t}= & \rho_{i} y_{i t-1}+\alpha_{i 0}^{*}+\delta_{i} D U_{i t-1}+\theta_{i} D\left(T B_{i}\right)_{t} \\
& +\sum_{j=1}^{k} \beta_{i j} \Delta y_{i t-j}+e_{i t},
\end{aligned}
$$

with $\alpha_{i 0}^{*}=\Psi_{i}^{*}(1)^{-1} \alpha_{i}\left(1-\rho_{i}\right), \delta_{i}=-\phi_{i} \theta_{i}, \phi_{i}=\left(\rho_{i}-1\right)$, $D\left(T B_{i}\right)_{t}=1$ if $\left(t=T B_{i}+1\right)$ and $k$ the optimal lag-length defined as the minimum lag-order producing serially uncorrelated residuals.

The unit root hypothesis can be tested using the $t$-statistics of the test on $H_{0}: \rho_{i}=1, t_{\rho_{i}}$. In order to construct the dummy variables of the test regressions and subsequently compute the test statistics, the true break date for each $i$ in the panel, $T B_{i}$, has to be estimated. To this end, we use the following method:

$\widehat{T B}_{i}=\arg \max _{T B_{i}}\left|t_{\hat{\theta}_{i}}\left(T B_{i}\right)\right|$.

In (4), $\widehat{T B}_{i}$ is chosen in such a way that the absolute value of the $t$ statistic $\left|t_{\hat{\theta}_{i}}\left(T B_{i}\right)\right|$ for testing the significance of the break dummy $\theta$ is maximized for each $i$.

\subsection{Combinations tests}

The basic idea of the combination tests is to combine the $p$ values of the $t$-statistics $t_{\rho_{i}}$ in the regression (3) for each unit $i$ in the panel. ${ }^{2}$ The null hypothesis of the panel unit root tests is $H_{0}: \rho_{i}=1$ for all $i$, while the alternative is $H_{1}:\left|\rho_{i}\right|<1$ for some i's.

Assume that $p_{i}$ is the asymptotic $p$-value of the Perron-type test for each $i$. We consider the following panel tests:

$P_{m}=-\frac{1}{\sqrt{N}} \sum_{i=1}^{N}\left[\ln \left(p_{i}+1\right)\right] \underset{N, T \rightarrow \infty}{\Longrightarrow} N(0,1)$

$Z=\frac{1}{\sqrt{N}} \sum_{i=1}^{N} \Phi^{-1}\left(p_{i}\right) \underset{N, T \rightarrow \infty}{\Longrightarrow} N(0,1)$

$L=\frac{1}{\sqrt{\pi^{2} N / 3}} \sum_{i=1}^{N} \ln \left(\frac{p_{i}}{1-p_{i}}\right) \underset{N, T \rightarrow \infty}{\Longrightarrow} N(0,1)$,

where $p_{i}$ is the $p$-value of the test proposed and $\Phi(\cdot)$ denotes a standard normal cumulative distribution function. In order to construct the panel tests, we need to compute the $p$-values of the innovational outlier distribution. To calculate the percentile of the innovational outlier test, we use a response surface methodology proposed in MacKinnon (1994). The data generating process under the null hypothesis $H_{0}$ is written as follows:

$y_{t}=D(T B)_{t}+z_{t}, z_{t}=\rho z_{t-1}+e_{t}, \quad(t=1, . ., T+50)$

where the break fraction $\lambda \sim U(0.1,0.9)$ and $e_{t} \sim N(0,1)$. Sample series of $y_{t}$ are generated by setting the initial value $z_{0}$ equal to 0

\footnotetext{
1 Popp (2008) shows that the criteria in (4) gains the best performance among other methods.

2 Bai and Carrion-i-Silvestre (2009) also use panel combination tests with structural breaks and cross-dependence.
}

and creating $T+50$ observations where the first 50 are discarded. The following steps summarize the method used to compute the p-values:

Step 1: Generate $\left\{y_{t}\right\} I$ times at $T=30,33,35,37,40,43,45,50$, $55,60,65,70,75,80,90,100,125,150,175,200,225,250,275$, 300 and $\lambda=0.1,0.2, \ldots, 0.9$. The $k$-lag parameter has been set using Schwert (1989) criterion, i.e. fixing $k=\left[12(T / 100)^{(1 / 4)}\right]$ where [..] indicates the integer values. ${ }^{3}$ The number of replications is $I=10000$.

Step 2: For each $T$ and $\lambda$ calculate 399 equally spaced percentile of the innovational outlier test. This gives a $24 \times 9$ by 399 matrix denoted as $\left[q^{p}(T, \lambda, k)\right]$ for $p=0.0025,0.0050, \ldots, 0.9975$.

Step 3: Estimate the regression equation

$$
\begin{aligned}
q^{p}(T, \lambda, k)= & \theta_{\infty}+\sum_{i=1}^{2} \theta_{i}(1 / T)^{i}+\sum_{j=1}^{2} \gamma_{j}(\lambda / T)^{j} \\
& +\sum_{j=1}^{2} \omega_{s}(\sqrt{k} / T)^{s}+\varepsilon_{T, \lambda, k},
\end{aligned}
$$

for each $p$ by using the restricted-OLS method. The Newey-West method has been applied to ensure heteroscedasticity-consistent standard errors estimates of the parameters. Furthermore, following MacKinnon (1991), we have regarded as insignificant those regressors for which the $t$-statistic in (9) was less (in absolute value) than unity. ${ }^{4}$

\section{Bootstrap procedure}

The sieve bootstrap procedure consists of five steps:

Step 1: For each $i=1, \ldots, N$ we estimate (3) with the original data under the null hypothesis $(\rho=1)$, i.e. we run the regression

$y_{i t}=y_{i t-1}+\theta_{i} D\left(T B_{i}\right)_{t}+\sum_{j=1}^{k} \alpha_{j} \Delta y_{i t-j}+\varepsilon_{i t}$

and then select the break using (4). Note that it is necessary to impose the null of a unit root when generating the artificial data in bootstrap unit root tests in order to achieve consistency (see Basawa et al., 1991).

Step 2: Denote by $\hat{\alpha}_{j}$ and $\hat{\theta}_{i}$ the OLS estimators of $\alpha_{j}$ and $\theta_{i}$ and with $\hat{\varepsilon}_{i t}$ the OLS residuals in regression (10). In order to preserve the cross-correlation structure of the error term we follow Maddala and $\mathrm{Wu}$ (1999) and resample $\hat{\varepsilon}_{i t}$ with the cross-section index fixed, i.e. we resample $\hat{\varepsilon}_{t}^{0}=\left[\hat{\varepsilon}_{1 t}^{0}, \hat{\varepsilon}_{2 t}^{0}, \ldots, \hat{\varepsilon}_{N t}^{0}\right]^{\prime}$, where $\hat{\varepsilon}_{i t}^{0}$ are now centered residuals $\left(\hat{\varepsilon}_{i t}-\bar{\varepsilon}_{i}\right)$ with $\bar{\varepsilon}_{i}=\sum_{t=1}^{T} \hat{\varepsilon}_{i t} / T$, in order to get $\hat{\varepsilon}_{t}^{*}=\left[\hat{\varepsilon}_{1 t}^{*}, \hat{\varepsilon}_{2 t}^{*}, \ldots, \hat{\varepsilon}_{N t}^{*}\right]^{\prime}$.

Step 3: Generate the pseudo sample $y_{i t}^{*}$ using the OLS estimates $\hat{\alpha}_{j}, \hat{\theta}_{i}$ and the residuals $\varepsilon_{i t}^{*}$, i.e.

$y_{i t}^{*}=y_{i t-1}^{*}+\hat{\theta}_{i} D\left(T B_{i}\right)_{t}+\sum_{i=1}^{k} \hat{\alpha}_{j} \Delta y_{i t-j}^{*}+\varepsilon_{i t}^{*}$.

Note that the previous regression (11) must be initialized to obtain the bootstrap sample. We fix the first $k$ of $y_{i k}^{*}$ to zero in order to avoid possible explosive autoregressive processes.

Step 4: We first run (3) by using the pseudo sample $y_{i t}^{*}$, and then we compute the $t$-statistics $t_{\rho_{i}}$, the corresponding $p$-value $p_{i}$ and the $P_{m}^{b}, Z^{b}$ and $L^{b}$ tests using (5)-(7).

\footnotetext{
3 For $T \leq 75$, we use $k=\left[4(T / 100)^{(2 / 9)}\right]$ in order to save degrees of freedom.

4 For reason of space, the estimated coefficients of the response surface regression are not reported. They are available upon request.
} 
Table 1

Rejection frequencies at the 5\%-level of significance of tests.

\begin{tabular}{|c|c|c|c|c|c|c|c|c|}
\hline \multirow[t]{2}{*}{$\theta$} & \multirow[t]{2}{*}{$T$} & \multirow[t]{2}{*}{$N$} & \multicolumn{3}{|c|}{$\rho=1$} & \multicolumn{3}{|c|}{$\rho=0.9$} \\
\hline & & & $P_{m}$ & $Z$ & $L$ & $P_{m}$ & $Z$ & $L$ \\
\hline 0 & 50 & 10 & 6.5 & 5.8 & 6.0 & 67.9 & 72.6 & 69.2 \\
\hline 0 & 50 & 25 & 6.4 & 5.7 & 5.9 & 81.3 & 87.7 & 82.9 \\
\hline 0 & 100 & 10 & 6.4 & 5.7 & 5.9 & 77.1 & 88.4 & 78.6 \\
\hline 0 & 100 & 25 & 6.3 & 5.6 & 5.7 & 89.4 & 96.7 & 91.2 \\
\hline 0 & 200 & 10 & 6.1 & 5.6 & 5.7 & 88.8 & 95.4 & 90.5 \\
\hline 0 & 200 & 25 & 5.8 & 5.5 & 5.6 & 100.0 & 100.0 & 100.0 \\
\hline 4 & 50 & 10 & 5.7 & 5.5 & 5.7 & 67.5 & 72.2 & 68.9 \\
\hline 4 & 50 & 25 & 5.7 & 5.4 & 5.5 & 80.9 & 87.3 & 82.5 \\
\hline 4 & 100 & 10 & 5.7 & 5.4 & 5.6 & 76.7 & 88.0 & 78.2 \\
\hline 4 & 100 & 25 & 5.6 & 5.3 & 5.5 & 89.0 & 96.3 & 90.8 \\
\hline 4 & 200 & 10 & 5.5 & 5.4 & 5.5 & 88.3 & 94.9 & 90.1 \\
\hline 4 & 200 & 25 & 5.4 & 5.3 & 5.3 & 100.0 & 100.0 & 100.0 \\
\hline
\end{tabular}

Step 5: We repeat $B=5000$ times from Step 2 to Step 4 in order to obtain the critical values with a break under the null from the sorted vector of 5000 test-statistics. If we now define with $\mathbf{1}\{\}$ the indicator function and choose a significance level $\alpha$, then we reject $H_{0}$ of the $P_{m}, Z$ and $L$ tests if

$\frac{1}{B} \sum_{b=1}^{B} \mathbf{1}\left\{P_{m}^{b}>P_{m}\right\}<\alpha, \quad \frac{1}{B} \sum_{b=1}^{B} \mathbf{1}\left\{Z^{b}<Z\right\}<\alpha$,

$\frac{1}{B} \sum_{b=1}^{B} \mathbf{1}\left\{L^{b}<L\right\}<\alpha$,

respectively.

\section{Monte Carlo study}

To examine the small sample properties of the bootstrap tests under cross-section correlation, we consider the following data generating process:

$y_{i t}=D\left(T B_{i}\right)_{t}+z_{i t}$

$z_{i t}=\rho_{i} z_{i t-1}+\varepsilon_{i t}$

$\varepsilon_{i t}=\gamma_{i} f_{t}+e_{i t}$

where $f_{t} \sim$ i.i.d.N $(0,1), e_{i t} \sim$ i.i.d.N $\left(0, \sigma_{i}^{2}\right)$, with $\sigma_{i}^{2} \sim$ $U[0.5,1.5]$, and $\gamma_{i} \sim$ i.i.d.U[-1, 3]. In the Monte Carlo analysis it is assumed that the true break lies in the middle of the sample, $\lambda_{i}=T B_{i} / T=0.5$. All simulations are based on 5000 replications of $y_{i t}$ and were carried out in GAUSS. To avoid any effect of the initial observation, $T+50$ observations are generated and the first 50 discarded. Two different values for the break parameter $\theta$ are considered, namely 0,4 . Results regarding size and power are reported in Table 1 . Size is computed at the $5 \%$ nominal significance level. The best finite sample performance is obtained with the $Z$ test which shows an empirical size very close to $5 \%$ nominal level. A slightly larger empirical size is observed with the $P_{m}$ test. With respect to the finite-sample properties of the power, results show that the power increases as $T$ and $N$ increase.

\section{Empirical results}

The new panel innovational outlier unit root tests are applied to a panel of 22 OECD inflation rates over the period 1978:1-2009:4. Other studies have investigated the stationarity properties of the inflation rate for OECD countries in presence of structural breaks using panel tests (see Costantini and Lupi, 2007, Basher and Westerlund, 2008, among others). The inflation rates are computed as the rate of growth of the consumer price index (HCPI) using quarterly data from OECD Prices Indices (MEI) data-set. In Table 2
Table 2

Univariate and panel unit root results.

\begin{tabular}{|c|c|c|c|c|c|c|}
\hline & \multicolumn{3}{|c|}{ Test results } & \multicolumn{3}{|c|}{$\begin{array}{l}\text { Bootstrapped critical } \\
\text { values }\end{array}$} \\
\hline & Statistics & $T B$ & $k$ & $1 \%$ & $5 \%$ & $10 \%$ \\
\hline \multicolumn{7}{|c|}{ Univariate tests } \\
\hline Australia & -5.206 & 2000:04 & 1 & -3.681 & -3.180 & -2.858 \\
\hline Austria & -1.106 & 1984:02 & 4 & -3.766 & -3.148 & -2.825 \\
\hline Belgium & -3.235 & 2001:03 & 4 & -3.873 & -3.210 & -2.926 \\
\hline Canada & -2.257 & 1991:02 & 4 & -3.944 & -3.309 & -3.007 \\
\hline Denmark & -3.708 & 1986:03 & 4 & -3.839 & -3.255 & -2.954 \\
\hline Finland & -2.811 & 1983:01 & 4 & -3.777 & -3.080 & -2.770 \\
\hline France & -3.390 & 1982:04 & 4 & -3.682 & -3.070 & -2.742 \\
\hline Germany & -0.914 & 1993:02 & 4 & -3.883 & -3.352 & -3.050 \\
\hline Greece & -2.072 & 1986:01 & 4 & -3.827 & -3.221 & -2.877 \\
\hline Ireland & -1.894 & 1981:02 & 3 & -3.677 & -3.006 & -2.697 \\
\hline Italy & -3.550 & 1981:04 & 4 & -3.641 & -2.987 & -2.683 \\
\hline Japan & -5.170 & 1989:03 & 4 & -4.031 & -3.360 & -3.015 \\
\hline Luxembourg & -2.836 & 1986:03 & 4 & -3.904 & -3.258 & -2.919 \\
\hline Netherlands & -1.025 & 1983:02 & 4 & -3.724 & -3.091 & -2.775 \\
\hline New Zealand & -1.250 & 1987:01 & 1 & -3.723 & -3.203 & -2.902 \\
\hline Norway & -4.552 & 2003:02 & 4 & -3.947 & -3.204 & -2.874 \\
\hline Portugal & -2.413 & 1983:02 & 4 & -3.692 & -3.103 & -2.795 \\
\hline Spain & -3.093 & 1985:04 & 4 & -3.749 & -3.181 & -2.858 \\
\hline Sweden & -2.352 & 1990:02 & 4 & -3.937 & -3.363 & -3.023 \\
\hline Switzerland & -2.739 & 1990:01 & 4 & -3.878 & -3.267 & -2.974 \\
\hline UK & -2.301 & 1991:03 & 4 & -4.019 & -3.350 & -3.002 \\
\hline USA & -2.200 & 1983:01 & 3 & -3.743 & -3.095 & -2.774 \\
\hline \multicolumn{7}{|l|}{ Panel tests } \\
\hline $\mathrm{Pm}$ & 7.985 & & & 4.961 & 2.924 & 2.060 \\
\hline $\mathrm{Z}$ & -5.009 & & & -3.989 & -2.862 & -2.215 \\
\hline $\mathrm{L}$ & -5.852 & & & -4.143 & -2.831 & -2.183 \\
\hline
\end{tabular}

Notes: $k$ and TB denote the lag order and the selected break date respectively.

unit root test results are reported. In the univariate case, evidence of stationarity is found for Australia, Japan and Norway at $1 \%$ significance level, for Belgium, Denmark, France, Japan, and Italy at $5 \%$ significance level, and for Finland and Spain at $10 \%$ on the basis of the bootstrapped critical values. With respect to the panel case, the null hypothesis of unit root is rejected at $1 \%$ significance level with all panel statistics on the basis of the bootstrapped critical values. In synthesis our results are in favor of the " $I(0)$ plus breaks" hypothesis for the inflation rate.

\section{References}

Bai, J., Carrion-i-Silvestre, J.L., 2009. Structural changes, common stochastic trends, and unit roots in panel data. Review of Economic Studies 76, 471-501.

Baltagi, B.H., Kao, C., 2000. Nonstationary panels, panel cointegration, and dynamic panels: a survey. In: Baltagi, B. (Ed.), Nonstationary Panels, Panel Cointegration, and Dynamic Panels. In: Advances in Econometrics, vol. 15. JAI Press, Amsterdam, pp. 7-51

Basawa, I., Mallik, A., McCormick, W., Reeves, J., Taylor, R., 1991. Bootstrapping unstable first-order autoregressive processes. Annals of Statistics 19, 1098-1101. Basher, S.A., Westerlund, J., 2008. Is there really a unit root in the inflation rate? more evidence from panel data models. Applied Economics Letters 15, 161-164.

Choi, I., 2001. Unit root tests for panel data. Journal of International Money and Finance 20, 249-272.

Costantini, M., Lupi, C., 2007. An analysis of inflation and interest rates. New panel unit root results in the presence of structural breaks. Economics Letters 95, 408-414.

MacKinnon, J., 1991. Critical values for cointegration tests. In: Engle, R., Granger, C.W.J. (Eds.), Long-Run Economic Relationships: Readings in Cointegration. Oxford University Press, New York, pp. 267-287.

MacKinnon, J., 1994. Approximate asymptotic distribution functions for unit-root and cointegration. Journal of Business \& Economic Statistics 12, 167-176.

Maddala, G.S., Wu, S., 1999. A comparative study of unit root tests with panel data and new simple test. Oxford Bulletin of Economics and Statistics 61, 631-652.

Perron, P., 1989. The great crash, the oil price shock, and the unit root hypothesis. Econometrica 57, 1361-1401.

Popp, S., 2008. New innovational outlier unit root test with a break at an unknown time. Journal of Statistical Computation and Simulation 78, 1145-1161.

Schwert, D., 1989. Tests for unit roots: A Monte Carlo investigation. Journal of Business and Economic Statistics 7, 147-159. 